\title{
A Spotlight on Environmental Psychology and Sustainability with Dr. Susan Clayton
}

\author{
Fanli Jia $^{1, * \mathbb{D}}$, Kendall Soucie ${ }^{2}$ and M. Kyle Matsuba ${ }^{3}$ (D) \\ 1 Department of Psychology, Seton Hall University, South Orange, NJ 07079, USA \\ 2 Department of Psychology, University of Windsor, Windsor, ON N9B 3P4, Canada; ksoucie@uwindsor.ca \\ 3 Department of Psychology, Kwantlen Polytechnic University, Surrey, BC V3W 2M8, Canada; \\ kyle.matsuba@kpu.ca \\ * Correspondence: fanli.jia@shu.edu
}

check for updates

Citation: Jia, F.; Soucie, K.; Matsuba, M.K. A Spotlight on Environmental Psychology and Sustainability with Dr. Susan Clayton. Sustainability 2021, 13, 5830. https://doi.org/10.3390/ su13115830

Received: 13 May 2021

Accepted: 19 May 2021

Published: 22 May 2021

Publisher's Note: MDPI stays neutral with regard to jurisdictional claims in published maps and institutional affiliations.

\section{Introduction}

To raise the global awareness of environmental psychology and sustainability in this Special Issue, we requested a virtual interview with Dr. Susan Clayton, one of the authors in the Special Issue. Dr. Clayton is a pioneer and one of the first researchers to examine how people think about and make personal connections to the natural environment. She has developed the Environmental Identity Scale to assess how the natural environment plays an important role in people's sense of selves. The scale has been applied to many different areas of psychology. Dr. Clayton has also developed the Climate Change Anxiety Scale to assess people's social and emotional responses to natural environment changes. Her research has not only contributed to the areas of environmental/conservational psychology, but she has also integrated developmental, educational, social, and cultural aspects into her work. Currently, Dr. Clayton is a lead author for the next assessment report from the Intergovernmental Panel on Climate Change.

\section{Interview}

Dr. Fanli Jia (FJ): Please tell us a bit about your work on the environment on identity, which has inspired many researchers for the past 18 years, including me. And what encouraged you to explore this topic?

Dr. Susan Clayton (SC): Yeah, it was really reading what people had to say about their own relationship to the natural world and listening to people, including some of my students, that made me realize that the environment did have this psychological significance for them. So, I would say specific quotes that I read in essays or specific things my students said in class. Before that I'd been mostly thinking of my environmental interests as separate from my psychological interest. But I realized, no, this is very deep, this is very meaningful. So then I started to read in the identity literature, which I wasn't that familiar with, and try and think about how that applied to environmental identity.

FJ: I was fascinated by Erik Erikson's psychosocial theory of identity development. Before my graduate training, I came across your work at a conference in Toronto where you talked about environmental identity a long time ago. I thought that was very interesting. And then I went to a graduate school where I examined moral identity and narrative identity from developmental and cultural aspects. Then finally, I integrated moral and narrative into environmental identity. So that's kind of like, at the time, I really focused on your work. So it took me a while.

$S C$ : Yeah. It can take a while, you hear these things and they stick in your brain and then maybe it takes a few years for them to develop into your research ideas.

FJ: You published an updated environmental identity scale [1] in our Special Issue and test the scale in different sample and cultures. Three samples from the United States, 
one sample from Russia, one from Taiwan, and one from [the] Swiss. Why are culture and diversity important in the field?

SC: Yeah, of course, culture and diversity are important across the field of psychology. As we want to be able to describe humans, we have to recognize what is stable and what isn't stable across cultures. We have to be more inclusive in our research focus. I think culture is particularly relevant here because identity and the person's relationship with nature and even the way they construct the idea of nature is very much affected by the culture they grew up in. I did a study a while back, maybe 10 years or so, in Turkey [2], looking at the relationship between national identity and environmental identity there and comparing that to the US, and it was quite different in Turkey. They at least perceived much more support for valuing the environment.

Whereas I think in the US, that was less true. So in the US, national identity and environmental identity were completely uncorrelated. So I think it just shows an example of how the values and belief systems you grew up with affect the way you value nature and, see yourself as related to it. I think we're increasingly aware that a lot of indigenous societies construct the relationship between humans and the natural world in a very different way than, you know, mainstream Western societies do. So there's a lot of diversity there.

$F J$ : Yeah, research on environmental psychology within indigenous cultures has been scarce. There is a study about Native American children's understanding of the natural environment [3]. At the beginning, researchers used a traditional method like plastic toy animals in hypothetical situations to measure human-animal interaction. A Native American research member rejected the method because Native American children would view the plastic animals alone as unnatural and ecologically inappropriate on perceiving nature.

I have also conducted several studies in China, Canada, and the USA. I found environmental norms were different in these countries, especially in China [4-6], where household waste managing programs were just formally introduced and became mandatory in 2019 . You have some articles conducted in China as well. One recent paper in Environmental Education Research [7], you examined environmental literacy in Chengdu, China. Could you tell us about how you established the collaboration in China?

SC: It was really just luck and coincidence. My university had a kind of travel study program for faculty. The president was very interested in having a group of faculty go to China one year. I reached out on the internet and I said, "I'm going to China. Does anybody have any connections with people I could meet there?" Terry Maple, who is a very well-known, comparative psychologist who used to run the Atlanta zoo, gave me the name [of a woman, Sarah Bexell], who worked in Chengdu at the Panda base. I was able to visit the base and meet some of her colleagues and coworkers.

And over the years she invited me back several times to work with them on some projects about how people were relating to the Pandas [8]. And then just that study about environmental literacy in environmental education at different levels in China [7]. I've actually been to China at least five times. I briefly tried to learn Mandarin and gave up. It was just too hard. It's just very fascinating because there are huge cultural differences there. Thinking about how people think about their relationship with the natural world and also the extent to which it is threatened and the individual role in addressing those issues too, I think are all very different there.

FJ: For the past 30 years, you have devoted your research on the environment and climate change, what do you consider your three most important observation?

$S C$ : Yeah, I should say I haven't been working on environmental issues that whole time. It took me about 10 years to kind of get to that place. But, I don't know how broad you want me to be, but one very broad conclusion I would say is that, you know, psychology has a role to play in addressing environmental issues such as climate change obviously but also loss of biodiversity. So, that would be the message that I would proclaim the loudest from the rooftops is that psychologists need to be aware of this and other people need to be aware of this. The second would be that personal identity does affect the way we respond to environmental issues. If we really need to understand how people are going to 
be affected by environmental changes and what they're going to do about them, we need to think about that personal identity and sense of self. I guess the third would just be the message that climate change is going to have a psychological impact on mental health and wellbeing and also on social relations. So we really need to be examining those impacts.

FJ: I plan to propose a course for environmental psychology. I got your textbook, Conservation Psychology [9]. I think the three components you have mentioned are in the textbook. Students should be interested in reading this book about how human and environment are connected. To follow up the question, what do you think is the future direction of this work in the field of environmental psychology?

$S C$ : I think people are going to be, and should be, more interdisciplinary-talking to economists, talking to ecologists, talking to public health officials, and also just incorporating more of the subdisciplines within psychology. I think most of us who are working on sort of environmental psychology were trained in maybe social or personality psychology. But increasingly there's awareness of developmental and clinical. I think we need to get organizational behavior kinds of people involved. There's some really interesting work by cognitive psychologists, so we need more of that. Some beginning evidence of sort of the neuroscience of environmental impacts, so definitely, crossing more of those borders.

I think people need to pay more attention to the impact of their research. I totally support basic research. I don't think all research has to be applied. But we could do more to, especially if we are trying to do applied research, to do more to think about, have I picked the best topic? Have I picked the best behavior? Is this research likely to have any impact whatsoever? I think those of us who are working in the environmental field are very aware that we're facing some serious challenges. It would be nice if our research could help those at least in some minor way or indirect way.

The third thing I'll end up with a sort of optimistic point is I think that there's much greater-and I'm sure you're aware of this-much greater awareness of the role that psychologists have to play. So I think there will be more opportunities to get involved in informing policy, applied applications, and in forming interdisciplinary teams. I think that will definitely affect the way we do our research.

FJ: Yes. That leads to the Special Issues my colleagues (Dr. Kyle Matsuba, an environmental psychologist, and Dr. Kendall Soucie, a developmental/health psychologist) and I, as a developmental/cultural psychologist, are organizing right now. I really liked that the Special Issue ideas that can gather all different subareas of psychology from an interdisciplinary perspective. We also had researchers from business, environmental policy, economics, and industries contribute their works in our Special Issue.

Could you give some advice for our journal Sustainability and especially the further direction of our Special Issue? (https://www.mdpi.com/journal/sustainability/special_ issues/Global_Environmentalism (accessed on 3 May 2021)).

SC: Yeah, that's a tough one because I thought about for me and the way I engage with this journal, and obviously I do read papers from it. I submit papers, I review papers. But there's so much published by this journal that it's kind of overwhelming. I wouldn't do anything like just skim through the table of contents. It just would take me too long, which is what I sometimes do for other journals. Like what's new in Journal of Environmental Psychology. Something that would help readers kind of filter the publications in Sustainability to say. These are the articles that's going to be useful to me or meaningful to me. Maybe even algorithms that would say, if you read this, you might also be interested in that. So that kind of thing, in terms of attracting more readers, targeted mailings, like this group might want to know about this Special Issue, for example. I like the Special Issue idea but there certainly seem to a lot of them.

FJ: How do you see open access publications or journals in your field, compared to traditionally subscribed journals?

SC: Open access is good. It's important. It makes the article readership available to people who might not otherwise have access, but, it's not free. The authors are paying instead of the readers. I don't have any funds from my institution to cover those kinds 
of costs. So increasingly maybe they can be incorporated into grants. Universities might have to get into the habit of making funds like this available, but I worry that, moving to more open access will disadvantage people at the less financially solid institutions or under-resourced countries too. One possibility is to have that option that you can publish it in a regular model, or you can pay extra and publish it open access. But that still suggests that more people will read the ones that are open access. So it's still a kind of disadvantage to the other people. So I don't have a good answer, honestly.

Conflicts of Interest: The authors declare no conflict of interest.

\section{References}

1. Clayton, S.; Czellar, S.; Nartova-Bochaver, S.; Skibins, J.C.; Salazar, G.; Tseng, Y.-C.; Irkhin, B.; Monge-Rodriguez, F.S. Crosscultural validation of a revised environmental identity scale. Sustainability 2021, 13, 2387. [CrossRef]

2. Clayton, S.; Kilinç, A. Proenvironmental concern and behavior in Turkey: The role of national and environmental Identity. PsyEcology 2013, 4, 311-330. [CrossRef]

3. Washinawatok, K.; Rasmussen, C.; Bang, M.; Medin, D.; Woodring, J.; Waxman, S.; Marin, A.; Gurneau, J.; Faber, L. Children's play with a forest diorama as a window into ecological cognition. J. Cogn. Dev. 2017, 18, 617-632. [CrossRef]

4. Jia, F.; Yu, H. Action, communication, and engagement: How parents "ACE" children's pro-environmental behaviors. J. Environ. Psychol. 2021, 74, 101575. [CrossRef]

5. Jia, F.; Yu, H. Brief data report on parent-child pro-environmental engagement across five cities in China. Data Brief 2021, 36, 106970. [CrossRef] [PubMed]

6. Jia, F.; Soucie, K.; Alisat, S.; Pratt, M. Sowing seeds for future generations: Development of generative concern and its relation to environmental narrative identity. Int. J. Behav. Dev. 2016, 40, 466-470. [CrossRef]

7. Clayton, S.; Bexell, S.M.; Xu, P.; Tang, Y.F.; Li, W.J.; Chen, L. Environmental literacy and nature experience in Chengdu, China. Environ. Educ. Res. 2019, 25, 1105-1118. [CrossRef]

8. Clayton, S.; Bexell, S.; Ping, X.; Zhihe, Z.; Jing, L.W.; Wei, C.H.; Yan, H. Confronting the wildlife trade through public education at zoological institutions in Chengdu, PR China. Zoo Biol. 2018, 37, 119-129. [CrossRef]

9. Clayton, S.; Myers, G. Conservation Psychology: Understanding and Promoting Human Care for Nature, 2nd ed.; John Wiley \& Sons: Hoboken, NJ, USA, 2015. 